\section{RECOVERY OF METALS FROM SCRAP*}

\author{
BY SIR HAROLD HARTLEY, C.B.E., F.R.S.
}

$\mathrm{T}$

HE dominant feature of industrial development in the nineteenth century was the use of power, but closely associated with it and of scarcely less importance was the enormous increase in the use of metals made possible by metallurgical progress. In 1800 , for example, the world production of iron and steel was about half a million tons; in 1900 it was forty million tons, and now is more than three times as great. This rapid growth in the use of metals made serious inroads into the world reserves of ores, and in some countries the available resources, particularly of the richest ores, were exhausted or seriously depleted; so that the problem of conservation has become urgent, and with this lies a close connexion with the question of the ultimate fate of metals in use and their recovery as scrap. To what extent are they lost in use ? Do they, in fact, follow man-made cycles like the well-known carbon and nitrogen cycles in Nature, so that the world stock is not in fact depleted ?

Unavoidable losses in the use of metals or alloys due to wear, corrosion, heat and dispersal dissipate them so that they cannot be recovered; similarly, their use in chemical compounds such as pigments tends as a rule to total loss. The only examples of metals in which there is little such wástage apart from their use in plating or in thin films are the socalled precious metals, gold, silver and the platinum group. An exact study of the fate of the industrial metals is impossible owing to the lack of accurate statistics and to the uncertainty as to their secondary uses, but it is clear that in this century scrap is playing an increasingly large part in metal production and must enter into any comprehensive survey of world metal supplies in the future.

In the United States, for example, it is estimated that in recent years (1929-38) ferrous scrap has amounted to 75 per cent of the output of steel, while non-ferrous scrap has accounted for 50,45 and 35 per cent of the total domestic consumption in all forms of copper, lead and aluminium respectively.

Each metal presents a different problem according to its nature and uses, but there are certain general aspects to be considered first in order to clarify so far as possible a somewhat confused picture.

\section{Definition of Scrap}

The word 'scrap' is used here to cover what are often described as secondary, reclaimed or runaround metals. Obviously there are different types of scrap which may be defined to indicate their origin as :

1. Process scrap. Scrap arising in the production of a finished or semi-finished article which is re-used in the plants of origin. This includes ingot heads, gates and risers from castings, crop ends of rolled material, trimmings from sheets, tubes, etc., all of which are normally returned to the melting furnaces in the same works.

2. Engineering scrap. Scrap such as swarf, drillings, turnings and rejects produced in engineering shops which are usually separated from the primary production, so that this scrap cannot be so quickly

* Paper read on July 25 at the Conference on Mineral Resources and International Relations of Science of the British Association. absorbed. Further, its physical character and high degree of oxidation often make it difficult to use in re-melting furnaces.

3. Old scrap. This consists of disused material arising from obsolescence, accident and worn-out parts. Recovery of this is a skilled trade involving the breaking-up of machinery into its component scrap categories ; for example, a motor-car is stated to contain no less than twenty-five different ferrous alloys and the same number of non-ferrous alloys.

It is, of course, impossible to make hard and fast distinctions between these three classes, particularly between 1 and 2, but these two classes cover new scrap, metal that has not been in service, as distinct from 3. Scrap of classes 2 and 3 may, however, easily get mixed in the process of collection before it reaches the producer again.

\section{Disposal of Scrap}

The disposal of scrap metals and their use to the best advantage is becoming more complicated each year owing to the increasing use of alloys. The whole problem would be vastly simpler if metals were used mainly in a pure state, or admixed in the case of iron with carbon alone. In many cases, for example bearing metals and tool steels, the alloys are kept separately in the process of collection for re-use after remelting and adjustment of their composition, as the recovery of the constituent metals from their alloys would be a wasteful and often a difficult and uneconomical operation. The sorting and classification of scrap is therefore a matter of great importance. For process scrap it is an easy matter, as this goes straight back to its own melting furnace. For engineering scrap the segregation is relatively easy if it is properly organized in each works, but the scientific sorting of old scrap presents much greater difficulties and requires careful organization to avoid waste. The higher prices paid for special alloys is an incentive to make the sorting as effective as possible. However, this is not so easy with small admixtures of alloy metals, and increasing dificulties are arising from the presence of these in undesirable quantities in the recovered metal.

One of the main difficulties of getting a true statistical picture of scrap recovery is the extent to which certain serap is re-used directly without coming into the market. This applies to all process scrap and to a certain amount of engineering scrap which is recovered directly; for example, brass turnings go back direct to the brass foundry. In large organiza. tions there is also a considerable re-use of old scrap which would not appear in any statistics. For example, railway chairs go back to the foundry, which may use as much as 95 per cent of old scrap. Bearing metals are also recovered internally and re-melted with the necessary additions of virgin metals which alone appear in the statistics. Similarly, copper scrap must reach the brass foundry unaccounted for, as the amount of copper used in brass making is less than the equivalent amount of zine which is known to be used for this purpose.

The picture is complicated further by the re-use of suitable old scrap for the direct manufacture of other articles. For example, the re-rolling of old rails to produce a variety of articles is carried out on a considerable but unrecorded scale, and locomotive axles can be forged down and heat treated for crank pins of smaller diameter, or used for many other purposes. Small bars of mild steel can be used for 
drop forgings. The re-fabrication of old scrap has been greatly helped in recent years by welding, and especially during the War has made considerable progress. Much of this re-use of scrap which makes a considerable contribution to the conservation of mineral resources does not appear in any statistical review.

\section{Relationship between Total Production and Scrap Recovery}

The volume of consumption at any moment depends on new demands and on replacements due to obsolescence, corrosion and wear and tear. It is therefore clear that unless there should be heavy accumulations of scrap or new demands had vanished in a severe depression, the amount of scrap arising from replacements must always be less than the total amounts of metal required for current production. The relation between the two will vary with the metal metal and the circumstances.

With the modern tendency to rapid development and quicker obsolescence, the life-cycle of metals will in general be shortened. On the other hand, welding has made possible the repair of steel, for example at rail ends and in locomotive fire boxes, which will increase the service life of metals. The development of improved materials with increased hardness, greater resistance to wear and fatigue, and to corrosion (including painting and surface treatment) also tends to lengthen the life-cycle and eliminate losses of metal. The use of lighter designs, the increasing use of sheet metal and of a multiplicity of small 'gadgets' may, however, tend to make scrap recovery less complete.

An interesting point arises in connexion with the increased use of reinforced concrete in place of steel construction. This effects a considerable saving of steel amounting to 50-60 per cent; but on the other hand it is not economical to recover much of the

RElative ATMOSPHeRIC CORRODIBILITY OF METALS

\begin{tabular}{|c|c|c|}
\hline Metal & $\begin{array}{l}\text { Friend }(J . \text { Inst. } \\
\text { Metals, } 42 ; 1929) . \\
7 \text { years in Birm- } \\
\text { ingham City air. } \\
\text { Loss of weight }(\%)\end{array}$ & $\begin{array}{c}\text { Hudson "Corrosion } \\
\text { of Iron and Steel" } \\
\text { (1940). Sheffield } \\
\text { industrial atmo- } \\
\text { sphere. } \\
\text { Rate of corrosion } \\
\text { (mils/year) }\end{array}$ \\
\hline Mild steel & $10 \cdot 3$ & $5 \cdot 0$ \\
\hline Wrought iron & $6 \cdot 7$ & $3 \cdot 8$ \\
\hline Cast iron & 3.5 (approx.) & Good resistance \\
\hline Zinc & 0.54 & $0 \cdot 70$ \\
\hline Nickel & 0.47 & $0 \cdot 41$ \\
\hline 7030 Brass $(2 \mathrm{~Pb})$ & $0 \cdot 39$ & 0.57 \\
\hline Copper & $0 \cdot 18$ & $0 \cdot 28$ \\
\hline Aluminium & $0 \cdot 11$ & 一 \\
\hline Tin & $0 \cdot 10$ & 一 \\
\hline Lead (soft) & 0.09 & 0.26 \\
\hline Stainless steel (12 Cr) & $0 \cdot 10$ & - \\
\hline $18 \mathrm{Cr} 8 \mathrm{Ni}$ & - & 0.003 \\
\hline
\end{tabular}

steel in reinforced concrete, wh9r эas the bulk of a steel frame can be salvaged.

For iron and steel, corrosion is the biggest factor, which Speller estimates may lead to an annual replacement of two por cent of the total tonnage in use. For other metals the effect is much less, as is shown in the accompanying table giving the results of exposure of metals in the industrial atmospheres of Birmingham and Sheffield. The two sets of results are expressed differently, but the metals appear in the same order in each.

When all these variable factors are taken into account and the uncertain statistics as to the use of scrap, it is not surprising that it is impossible to draw up an exact balance sheet covering losses and recovery of any metal, as will be seen in the sections dealing with the separate metals.

\section{Iron and Steel}

At present iron and steel represent about 93 per cent of the total world tonnage of mital production.

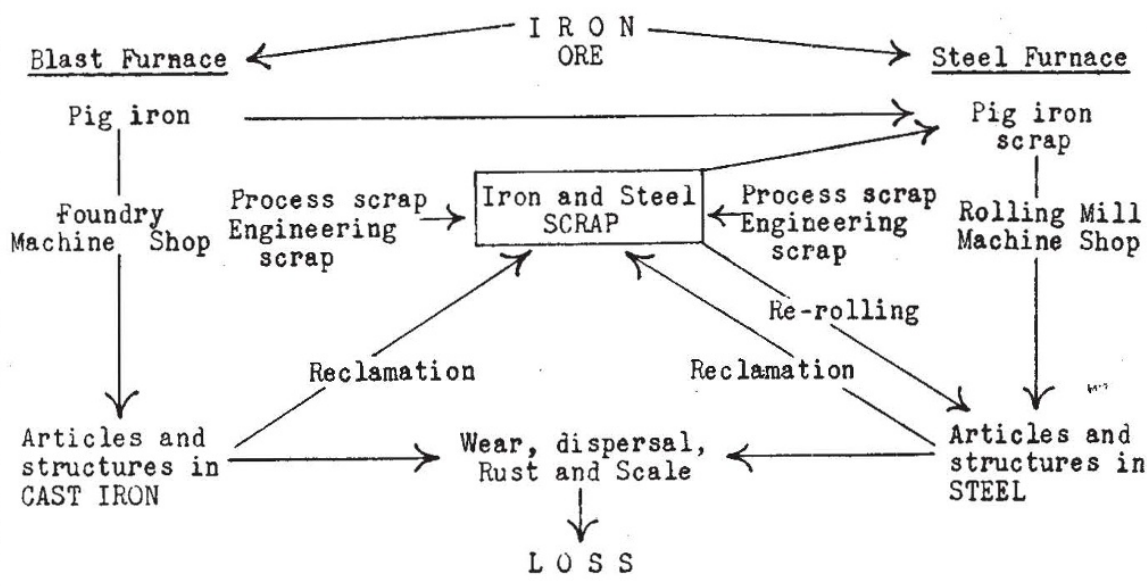

LIFE-CYOLE OF IRON

It has been estimated that of the total output, 15-20 per cent is lost from rusting, and that in all 35 per cent is lost irrecoverably due to rust, dispersal and the use of iron and steel in articles from which recovery is uneconomic. 65 per cent is left to find its way back into use, of which 25 per cent is process scrap which does not leave the steel works, and the remaining 40 per cent returns at a rate dependent on obsolescence, wear and the state of industrial activity. With improved protection against rusting, losses will be reduced, but quicker obsolescence will shorten the life-cycle.

The following figures for recent steel production in Great Britain confirm this estimate, remembering that some scrap goes to blast furnaces and that an addition must be made to the percentage of scrap in the table to allow for this:

$\begin{array}{cccccc}\text { Year } & & \begin{array}{c}\text { Total } \\ \text { production }\end{array} & \begin{array}{c}\text { Pig } \\ \text { used }\end{array} & \begin{array}{c}\text { Scrap } \\ \text { used }\end{array} & \begin{array}{c}\text { Scrap } \\ \text { (per cent) }\end{array} \\ 1935 & \ldots . . & 9.6 & 4 \cdot 6 & 5.8 & 56 \\ 1936 & \ldots . . & 11.8 & 5 \cdot 6 & 6.9 & 55 \\ 1937 & \ldots . . & 12.9 & 6.2 & 7 \cdot 5 & 55\end{array}$

The recovery of ferrous scrap in the United States has reached a higher figure in recent years, averaging 75 per cent of the steel production, possibly due to quicker obsolescence. 
The main difficulty which has arisen in the recovery of ferrous serap is due to the increase in the number of alloys, which makes it increasingly difficult to segregate scrap of similar character. The result is that the amount of the residual elements tends to increase in ordinary steel, producing undesirable results. For example, the presence of nickel and chromium may produce a steel very different in characteristics from the steel required. Rejection has occurred from this cause, emphasizing the importance of improved methods for segregating most carefully scrap from alloy steels of various compositions, in order to utilize them most economically and to avoid the presence of elements which may upset the normal properties of the steel. The introduction of controlled grain size straight carbon steels often avoids the need for using alloy steels, and they have the additional advantage of simplifying the recovery of scrap, since they contain no other elements.

In the case of alloys with a high percentage of other elements, for example stainless steel or tool ateels, the large differential in scrap price is an incentive to see that they are kept separate.

\section{Manganese, Nickel and Chromium}

There is only a small recovery of manganese in the form of high manganese alloys, as the bulk of it is used in steel manufacture as a deoxidizer and desulphurizer and is lost in the slag.

Only a small percentage of nickel is recovered, as much of it is lost in low-nickel steel alloys which go into ordinary scrap or in nickel plating. Undoubtedly more could be saved by the segregation of nickel alloys. Recovery is presumably better for the high-nickel alloys. In the United States scrap recovery has progressed steadily and in 1938 was about 2,000 tons.

Little is known about the recovery of chromium, except that its high price encourages recovery by producers and fabricators of the alloys and by large consumers. The expanding demands for chromium steels will make the segregation of chromium alloy scrap of increasing importance.

\section{Copper}

The United States statistics for copper recovery are more complete than for any other metal and so it is possible to give a clear picture of the position. Owing to its relative freedom from corrosion, wastage should be relatively small and its value is favourable for salvage.

Copper is recovered and passes into use again both as metal and as brass and other alloys, and it is important to distinguish between the two. United States statistics for 1929-38 show that, of the domestic consumption of copper metal, approximately $6 \frac{1}{2}$ million tons in those years, $2 \frac{1}{3}$ million tons, or 39 per cent, came from scrap recovery, of which roughly one third came from now scrap (process and engineering) and two thirds from old scrap. Scrap recovery in addition yielded nearly 2 million tons of copper in the form of brass or alloys. The total contribution of recovery, therefore, to the domestic use of copper in all forms was approximately 50 per cent for this period.

The trend of scrap recovery over a period of years shows a close relation to the index of industrial production. Increasing prosperity means new consumption and the quicker replacement of obsolescent articles. Increased production means increased new scrap, and the flow of old scrap depends on the rate of replacement. Apart from stocks this flow is, in fact, a direct function of current consumption. $\mathrm{Hn} \mathrm{ce}$ it is not surprising that the volume of scrap recovery of copper should be related more closely to the index of production than to current scrap prices. The length of the life-cycle of copper will vary with the level of industrial activity.

\section{Tin}

About half the total tin production is used as pure metal for making tinplate and as foil for various purposes. The rest is used in various alloys, solder, bearing metal and bronzes. Tin is recovered from the clean tin scrap and from the dross arising in the course of manufacture of tinplate, but the recovery of tin from used cans is not in general economical owing to the difficulty of collecting and cleaning them. There is also a considerable recovery from tin alloys. United States statistics for $1929-3$ show a recovery of metallic tin from scrap amounting to eight per cent of the total consumption as pure tin and alloy, and a recovery in the alloy form amounting to 26 per cent, so that on an average one third of the consumption was provided from the recovery of scrap. About 6 per cent of the tin is used in various chemical compounds and this is irrecoverable.

\section{Lead}

The major uses for lead are storage batteries, cable covering, sheet and pipe, and a small proportion is used in alloys. The processes of manufacture are relatively simple and they result in little process or engineering scrap. Owing to the relatively large percentage of lead used in pigments, in ammunition and as tetra-ethyl lead in motor spirit, and the loss of bearing metals by wear, there is inevitably a considerable irrecoverable loss. On the other hand, the recovery from storage batteries probably amounts to 80 per cent after an average cycle of two or three years in motor-vehicles, while the cable covering is also largely recovered after a longer period of years.

United States statistics for 1929-39 show that the recovery of lead as metal produced $1,349,000$ tons, one third of the total production of refined lead during that period, and that, in addition, 1,017,000 tons were recovered in the form of alloys, thus saving an equal quantity of virgin metal.

\section{Zinc}

A large proportion (probably 40 per cent) of zinc production is used for galvanizing iron to protect it against corrosion, and none of this is recovered, the zinc being sacrificed for the protection of the so-called iron, but which to-day is mild steel. However, there is a wastage of some 20 per cent of zine in the galvanizing pot, much of which is recovered as dross, which is re-distilled for spelter or zinc dust. The next largest use of zine is for brass-making, a considerable proportion of which is recovered and re-used. Apart from this, there is only a small recovery of zine from the articles in which it appears in the rolled form. The United States statistics show that the recovery of zinc as metal has averaged 11 per cent of metal production, and in addition slightly less has been recovered in the form of alloys. A considerable loss occurs each year from the use of zinc in pigments. 


\section{Aluminium}

There is a considerable scrap recovery of aluminium and aluminium alloys. Process scrap is usually remelted in the works when it is produced. Engineering scrap (turnings, millings, filings, etc.), which may amount to $50-200$ per cent of the weight of the finished article, requires special methods of melting to ensure both a good yield and quality and is usually returned to specialist firms, the secondary metal melters. The segregation and cleaning of the various types of scrap are of great importance.

Old scrap presents a more difficult problem, as it has to be separated into the different alloys, a skilled job requiring experience and the use of scientific methods.

United States statisties for 1929-38 show that out of a total production of one million tons of metal, one fifth came from scrap recovery. In addition, about 225,000 tons of aluminium were recovered in the form of various alloys, making the total contribution of scrap to consumption in this period about 35 per cent.

\section{Export of Scrap}

Nothing has been said yet about the export of scrap, but to secure maximum recovery there should be a flow back to metal-producing from non-producing countries. The statistics for iron and steel scrap, which are fairly complete, do show this in a few cases, such as Holland and Switzerland, but the bulk of the transfer of scrap, which averaged 5 million tons a year for 1933-38, actually took place between steel-making countries, owing largely to preparations for war. Under happier auspices the International Scrap Convention, established in 1937, might have done much to avoid this uneconomical transfer.

\section{Conclusion}

The absence of world statistics on the recovery of scrap makes it impossible to give a comprehensive picture of its full significance. However, it is clear from the data given above that scrap recovery will be of increasing importance as regards the conservation of our metal resources, and that as a major source of raw materials it must be brought into any general scheme affecting them under the Atlantic Charter.

Taking conservation first, the following measures would help towards a maximum scrap recovery and help to diminish wastage of metals : (1) The salvage of all new and as much old scrap as possible. (2) Improved methods for segregating engineering scrap of different kinds so as to avoid mixing different metals and alloys. (3) Improved methods for sorting and cleaning old scrap and identifying doubtful material by quick tests. (4) Improved methods for cleaning scrap and putting it into a suitable form for remelting. (5) Arrangements to avoid losses by corrosion when scrap, often finely divided, is kept for long periods. (6) Avoidance of the unnecessary use of alloys, which complicates scrap recovery, and the reduction of the number of alloy specifications to the minimum necessary. (7) Improved methods for protecting metals against corrosion. (8) The re-use of old scrap by fabrication and welding.

Turning now to the inclusion of scrap metals in any general scheme for metal supplies under the
Atlantic Charter, the first essential is the compilation of international statistics on an agreed basis. Even if these cannot be complete owing to the difficulty of including old scrap which is re-used by works internally, and so-called runaround scrap such as bearing metal, which circulates internally and therefore does not come into account, it should be possible to collect data for all process scrap, engineering scrap, or old scrap which reaches the market, so as to see to what extent consumption in each country can be met from virgin metal or from scrap.

The need for such statistics was emphasized in the following passage from the report of the National Resources Board of the United States appointed by President Roosevelt in 1934: "The subject of scrap is the great blind spot of the world's metal economy. Despite the importance of secondary metals no statistics of an international character can be had. The United States is the only Government compiling figures of secondary metal production. The present annual statistics of the Bureau of Mines should be established on a quarterly or monthly basis and expanded to include stocks and consumption as well as output. This is one of the most constructive steps that could be taken for stabilization of the metal industries. Until the importance of scrap is recognized, effective adjustment of supply and demand in the metal industries will remain difificult or impossible." This was written in 1935 with special reference to the United States; to-day, in the light of the Atlantic Charter, it has a much wider significance.

\section{FAMILY SIZE AND SURVIVAL IN GREAT BRITAIN}

\section{BY DR. PERCY STOCKS}

$\mathrm{T}$ HE Registrar-General's first report on fertility, based on the data obtained under the Population (Statistics) Act of 1938, shows that in 1938 the reproduction rate in England and Wales, adjusted for the anticipated rates of survival of women and girls, must have been between 16 and 20 per cent below the replacement level, and that if a serious decline in the native-born population of Great Britain is to be averted, the rate must be raised to that extent within the next few years. Complete elimination of stillbirths and child deaths up to age fifteen would bring us within $6-7$ per cent of the goal, but that is outside the bounds of possibility. The increase might be effected by less avoidance of marriage and by marriage at an earlier age, but if no such social changes as these occur, it can only come by increase in the average number of children per family.

The average citizen has little knowledge of a biological kind as to the best age for marriage and the most favourable spacing of children for the rearing of a healthy family, and even scientific men have to confess to a lamentable lack of concise information on these vital matters. It would be natural to expect, therefore, that any addition to such knowledge would be eagerly studied. Little comment has been made upon the facts revealed by the fertility report : such as the findings that 42 per cent of marital children 